\title{
Micromechanics of wastewater sludge floc: Force-deformation relationship at cyclic freezing and thawing
}

\author{
T. Tao ${ }^{\text {a }}$, X.F. Peng ${ }^{\text {a }}$, D.J. Lee ${ }^{\text {b,* }}$, J.P. Hsu ${ }^{\text {b }}$ \\ ${ }^{a}$ Thermal Engineering Department, Tsinghua University, Beijing, 100084, China \\ ${ }^{\mathrm{b}}$ Department of Chemical Engineering, National Taiwan University, Taipei, 10617, Taiwan
}

Received 21 November 2005; accepted 1 January 2006

Available online 21 February 2006

\begin{abstract}
This study examined shape changes in two typical wastewater flocs subjected to cyclic freezing and thawing and the associated force exerted by the ice front. While freezing, the engulfing ice front gradually pulled the floc apart. Subsequent thawing only partially restored the floc's shape. By the Maxwell model, used to interpret gross shape deformations, both flocs were visco-elastic objects exhibiting time-varying rheological characteristics which were more viscous than elastic. Detailed observations of floc 1 deformation demonstrated a two-stage force-displacement relationship. Following 1 cycle of freezing and thawing, the interior structure of the floc deteriorated and the force required to elongating a unit length of floc decreased by $60 \%$. The original floc 2 had a dense "core" and loose "tail"; the core was more resistant to deformation under normal stress than the loose tail. Although both flocs had similar shapes and sizes and were acquired from the same activated sludge stream at a wastewater treatment plant, their rheological behaviors differed substantially. A comprehensive theoretical model for freezing and thawing processes should incorporate these rheological characteristics as they corresponded to observed structural changes and reduction in bound water content in sludge following a cyclic treatment of freezing and thawing.
\end{abstract}

(c) 2006 Elsevier Inc. All rights reserved.

Keywords: Freezing; Thawing; Floc; Shape deformation; Force

\section{Introduction}

Freeze/thaw treatment as an effective sludge dewatering technique has attracted considerable attention [1-6]. Utilizing freeze/thaw treatment can markedly enhance particular sludge dewatering characteristics [7], (irreversibly) alter floc structure [8], and decrease bound water content [9]. When ice front advances in a suspension containing particles, the ice typically repels, pierces, breaks or entraps the solid particles ahead of the advancing ice front [10]. The degree of change in floc shape following freezing and thawing is correlated with the ice morphology produced during a test $[8,11,12]$.

The ice front and the surrounding fluid field forces acting on a wastewater sludge floc determine whether an ice front can engulf a floc. Micromanipulation was employed to measure floc rupture strength [13] and biofilm tensile strength [14]. Tao

\footnotetext{
* Corresponding author.

E-mail address: djlee@ntu.edu.tw (D.J. Lee).
}

et al. [15] first measured the force exerted on a solid polystyrene sphere of diameter $1676 \mu \mathrm{m}$ by an advancing ice front moving at $5 \mu \mathrm{m} / \mathrm{s}$. A gas bubble, which nucleated and enlarged between the sphere and ice front, exerted a maximum force on the sphere of 0.242 dynes. Without this bubble underneath the polystyrene sphere, the maximum force reduced to 0.04 dynes during freezing.

This study employed the apparatus developed by Tao et al. to cyclically freeze and thaw wastewater sludge flocs, and assess the forces exerted on a floc by an ice front and the related detailed shape deformations. Consequently, for the first time, this work demonstrates the micromechanics of wastewater sludge flocs before and after freezing. This experimental finding is essential to the development of a detailed scheme for sludge freezing treatment.

\section{Experiment}

This work evaluated two flocs, both were acquired from the recycling stream of a wastewater treatment plant for the 


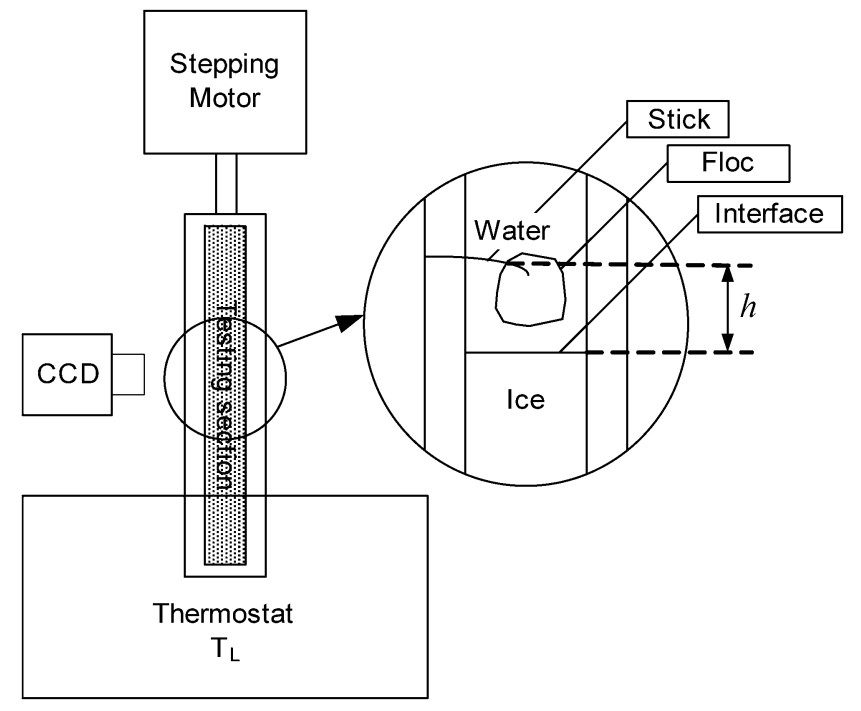

Fig. 1. Schematics of experiment setup.

Presidential Food Company, Taoyuan, Taiwan. This plant treats 250 tons/day wastewater from food processing utilizing primary, secondary, and tertiary treatment processes. The collected sludge sample was flocculated in a conventional baffled stirred tank using T3052, a cationic polyelectrolyte (MW of $10^{7}$ and $4.6 \mathrm{meq} / \mathrm{g}$ surface charge) provided by Kai-Guan Chemicals, Taiwan. Although both flocs were obtained from the same sludge sample, the internal structure of floc 1 (diameter, $2170 \mu \mathrm{m}$ ) was more compact than that in floc 2 (diameter, $2240 \mu \mathrm{m}$ ). Flocs 1 and 2 were hung on two cantilevered sticks with Hooke's constants of 0.0061 and $0.0029 \mathrm{~N} / \mathrm{m}$.

The experimental setup resembled that described in previous work $[15,16]$ (Fig. 1). A vertical temperature gradient was constructed. A complete cycle comprised a freezing and thawing stage. During freezing, the tested section made of optical glass, $150 \mathrm{~mm}(\mathrm{~L}) \times 50 \mathrm{~mm}(\mathrm{~W}) \times 5 \mathrm{~mm}(\mathrm{~T})$ in size, was immersed with the hung floc at constant speed into freezing water (HAAKE C35) of $-30^{\circ} \mathrm{C}$. Ice was advanced upward at $5 \mu \mathrm{m} / \mathrm{s}$. The motion and morphology of the sludge floc was observed until it was completely engulfed by the ice layer. Following the freezing stage, the container was pulled from the freezing pool to induce thawing at a specific speed. This process was repeated until the floc was torn apart by the ice. A digital camera, WAT WAT-505EX (Watec, Japan, 1/3 inch, $768 \times 576$ pixels), equipped with a close-up lens was employed to record floc shape and stick position. The images, scanned at $768 \times 576$ pixels per frame, were recorded continuously using the Orine frame grabber (Matrox, USA) and assessed at a workstation. The detailed shape deformation of the floc, vertical displacement of the stick, and ice interface-sphere distance $(h)$ were measured at a maximum error of $10 \mu \mathrm{m}$.

\section{Results and discussion}

\subsection{Freezing and thawing test}

The floc was cyclically frozen and thawed. Fig. 2 presents the freezing and thawing test for floc 1 at cycle 2 as a demon- strative example, with the black bars representing 1-mm scales. Other freezing and thawing tests for floc 1 and for floc 2 behaved similarly and are not shown here for sake of brevity. The test with a solid sphere of diameter $1676 \mu \mathrm{m}$ adopted from Tao et al. [15] is also presented in the figure (Figs. $2 \mathrm{~m}-2 \mathrm{p}$ ) for comparison.

The floc was initially far from the ice front which was in a flat shape (Fig. 2a). The ice front remained flat until it contacted the floc. This progression differs from that for a polystyrene sphere (Fig. $2 \mathrm{~m}$ ), during which the ice front was concaved downward as a result of significantly lower thermal conductivity of the sphere compared with that of water. As the ice front encased the bottom of the floc, the floc (with the cantilevered stick) was thrust upward and bubbles formed in and around the floc owing to the lower gas solubility in ice than in water (Figs. 2b and 2c). The expanding ice continuously elongated the floc (Figs. 2d-2g). At $t>142 \mathrm{~s}$, the floc was completely frozen (Fig. 2h).

During the following thawing stage, the test section was drawn upward out of the cool bath and the ice melted at a constant speed (Figs. 2i-2k). The shape of the floc was partially restored as it was released by the ice layer (Fig. 2l, discussed later).

\subsection{Shape deformation at cyclic freezing and thawing}

During freezing, the floc was pulled apart by the ice and during thawing, the shape of the floc was partially restored (Fig. 2). If the floc were a purely elastic object, then its original shape could be restored after thawing. If the floc were purely viscous, then the floc would retain its frozen shape after thawing. Tracking the shapes before and after freezing and thawing test provides useful data for the visco-elastic behavior of a floc.

Fig. 3 presents the shapes of floc 1 before and after freezing. Originally, floc 1 had a dense interior of $1680 \mu \mathrm{m}$ in length from the stick to the floc bottom, and was elongated to $2600 \mu \mathrm{m}$ when completely frozen (Fig. 3a). The corresponding lengths for cycles 2-4 were 2230 and $3270 \mu \mathrm{m}$ (Fig. 3b), 2550 and $4250 \mu \mathrm{m}$ (Fig. 3c), and 3670 and $4720 \mu \mathrm{m}$ (Fig. 3d), respectively. Hence, the floc interior had a visco-elastic characteristic. Additionally, the interior of the thawed floc was looser than that prior to freezing. The evolution in shape of floc 2 throughout freezing and thawing cycles 1-5 resembled those of floc 1 throughout cycles 1-4 (Fig. 4). The distance between the stick and floc bottom before and after freezing were 2037 and $2463 \mu \mathrm{m}$ (Fig. 4a), 2397 and $2639 \mu \mathrm{m}$ (Fig. 4b), 2569 and $2926 \mu \mathrm{m}$ (Fig. 4c), 2887 and $3274 \mu \mathrm{m}$ (Fig. 4d), 2952 and $3359 \mu \mathrm{m}$ (Fig. 4e), and 3000 and $3712 \mu \mathrm{m}$ (Fig. 4f) for cycles 1-6, respectively.

\subsection{Force-deformation relationship}

By utilizing Hooke's law, the force exerted by the cantilevered stick on top of the floc can be estimated. The maximum elongation forces acting on floc 1 throughout cycles 1-4 were $1.34,0.748,1.07$ and 1.51 dynes, respectively, and those for floc 2 throughout cycles $1-6$ were $0.428,0.214,0.297$, 


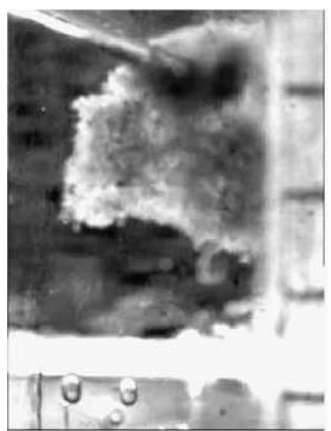

(a) $t_{f}=0 \mathrm{~s}$

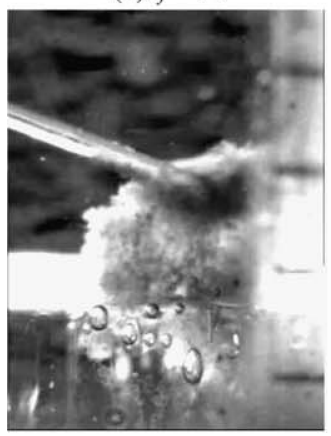

(e) $t_{f}=384 \mathrm{~s}$

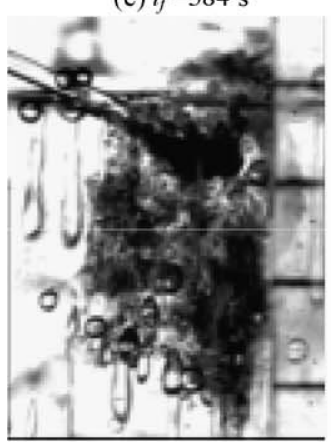

(i) $t_{t}=0 \mathrm{~s}$

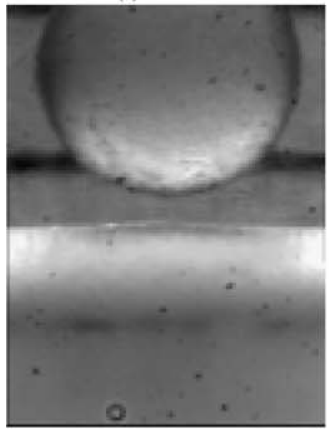

(m) $t_{f}=0 \mathrm{~s}$

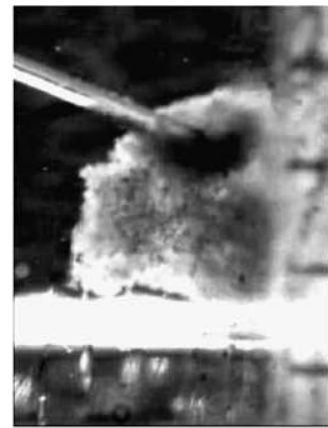

(b) $t_{f}=168 \mathrm{~s}$

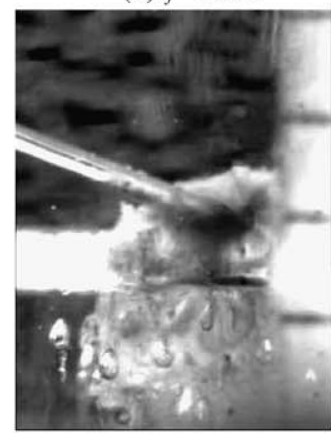

(f) $t_{f}=476 \mathrm{~s}$

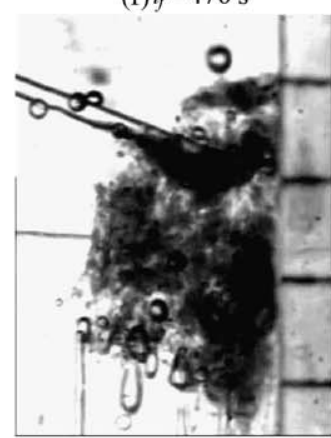

(j) $t_{t}=264 \mathrm{~s}$

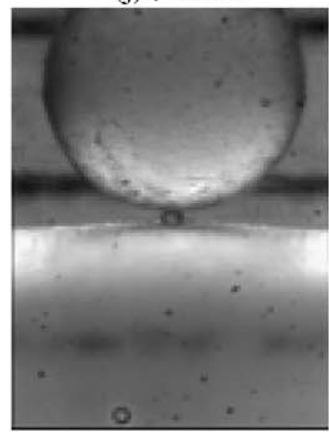

(n) $t_{f}=30 \mathrm{~s}$

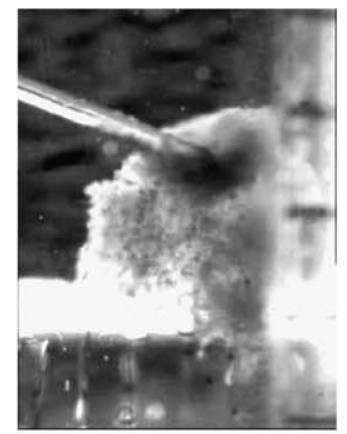

(c) $t_{f}=216 \mathrm{~s}$

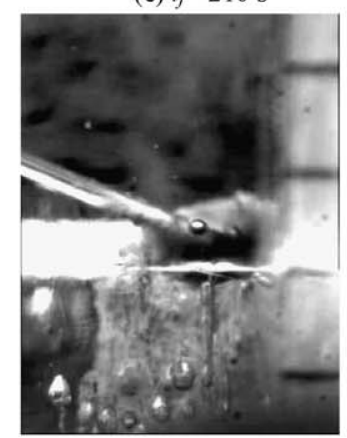

(g) $t_{f}=580 \mathrm{~s}$

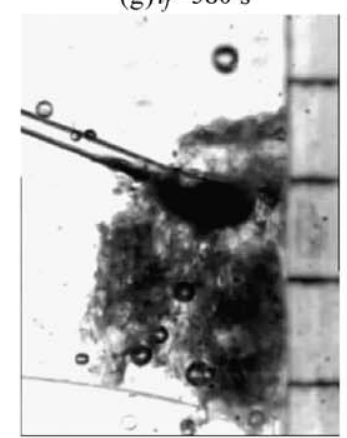

(k) $t_{t}=424 \mathrm{~s}$

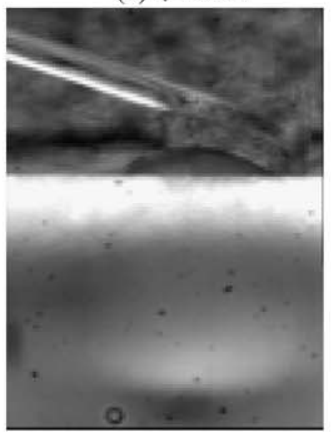

(o) $t_{f}=465 \mathrm{~s}$

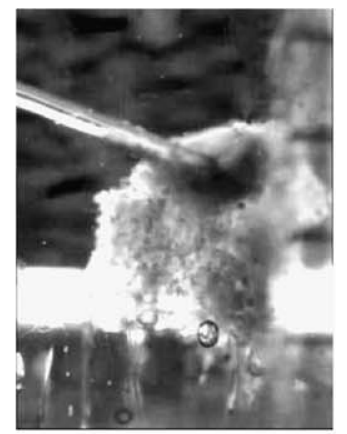

(d) $t_{f}=312 \mathrm{~s}$

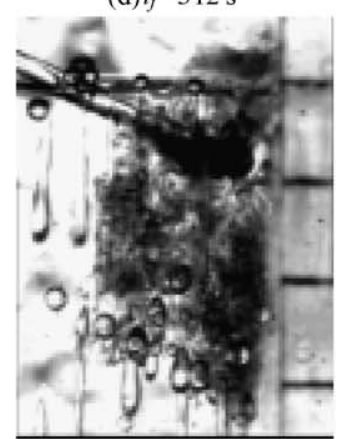

(h) frozen

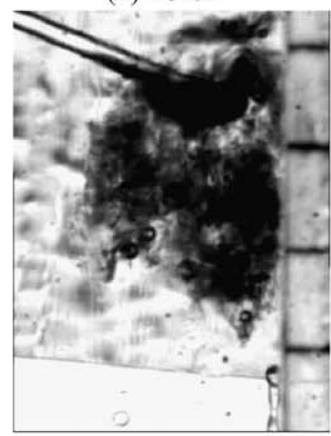

(1) thawed

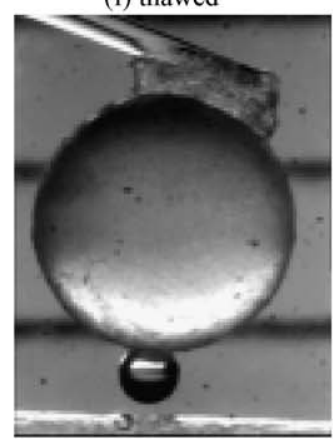

(p) thawed

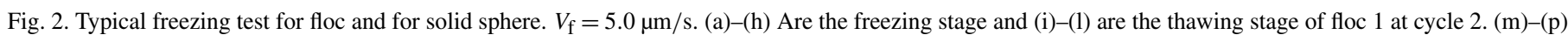
Are the freezing test of solid sphere adopted by Tao et al. (2004).

0.306, 0.347, and 0.316 dynes, respectively. Tao et al. [16] indicated that the forces applied by the top stick were equal to those applied to the floc by the bottom ice front. After cycle 1 , the interaction between ice and floc weakened, yielding a "minimum" maximum force applied by the stick in cycle 2 . In the following cycles, the force applied by ice increased accordingly. Both flocs showed the same trends, despite the ice front manifesting a larger force on floc 1 than on floc 2 .
The mechanical analogy characterizes the viscoelasticity of a floc subjected to an axial force. One of the simplest empirical models is the so-called Maxwell model, that addresses a spring of constant $G\left(F=-G D_{\mathrm{s}}\right)$ and a dashpot of viscosity $\mu$ ( $F=$ $\left.-\mu\left(\mathrm{d} D_{\mathrm{d}} / \mathrm{d} t\right)\right)$ connected in series. Hence, the displacement of floc $D$ is the sum of the spring and the dashpot. Hence, when the floc was completely frozen, the maximum force exerted was $D=D_{\mathrm{s}}+D_{\mathrm{d}}$. When the floc was thawed, no external force exerted, $D=D_{\mathrm{d}}$. 

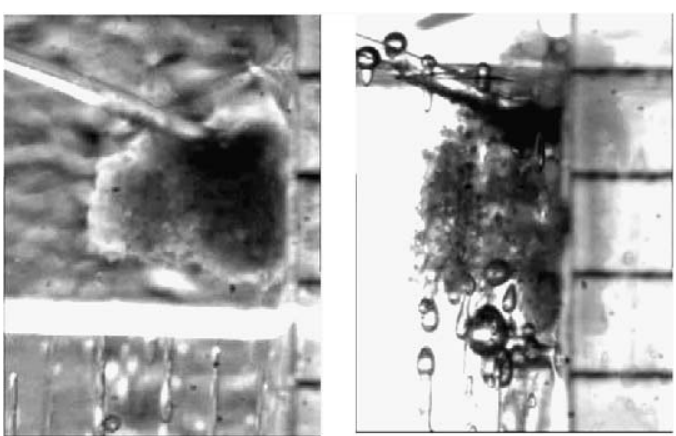

(a)
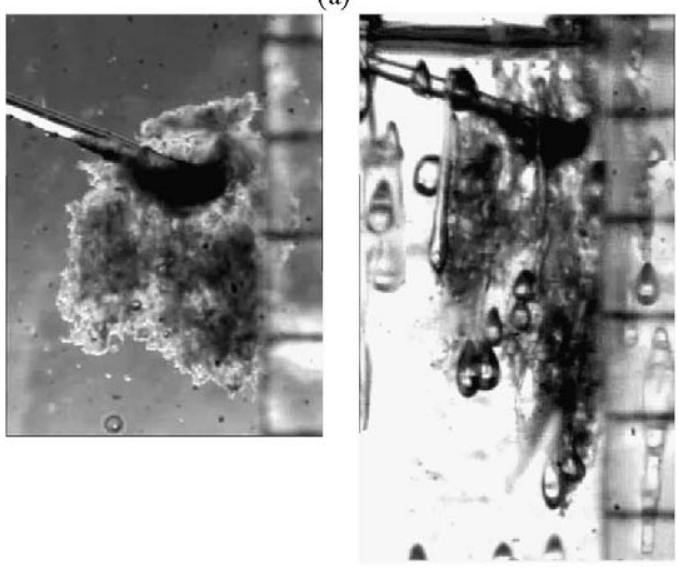

(c)
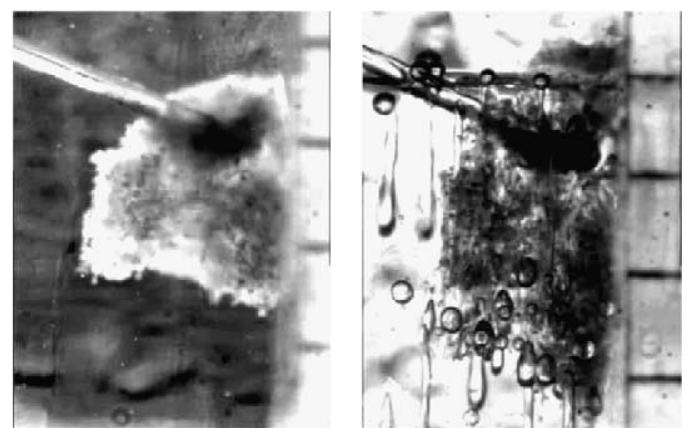

(b)
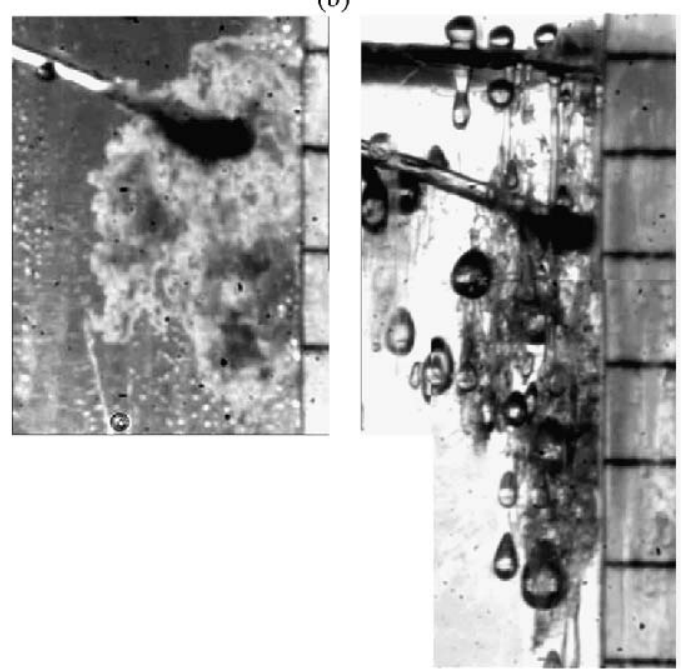

(d)

Fig. 3. Floc shapes before and after freezing and thawing. (a) Cycle 1; (b) cycle 2; (c) cycle 3; (d) cycle 4. Left panel in (b)-(d): after thawing and before freezing for the next cycle; right panel in (a)-(d): frozen floc.

With vertical length data recorded for flocs before and after freezing, the corresponding $D_{\mathrm{d}}$ and $D_{\mathrm{s}}$ for the Maxwell model in each cycle can be estimated. The original floc 1 had a vertical length of $1680 \mu \mathrm{m}$, which represented the no-stress length of the spring in the model (left panel of cycle 1 in Fig. 5). Then the ice pulled the floc apart under a maximum force of 1.34 dynes for a maximum displacement of $2600 \mu \mathrm{m}$, resulting from both the spring and dashpot in the model. After thawing, the spring restored its no-stress length $(1680 \mu \mathrm{m})$, whereas the irreversible displacement $(=2230-1680=550 \mu \mathrm{m})$ resulted from displacement of the dashpot in cycle 1 . Consequently, the spring length for a completely frozen floc during cycle 1 was estimated $(=2600-550=2050 \mu \mathrm{m})$. Repeating this calculation acquired the displacements for the spring and dashpot during cycles 2-3 for floc 1 and during cycles $1-5$ for floc 2 .

Fig. 6 presents the force-displacement relationships for flocs 1 and 2. Although flocs 1 and 2 were obtained from the same sludge sample, they had different stress-strain relationships. The viscous characteristics of both flocs deteriorated after cycle 1, and were restored after cycle 3 . Hence, the "state" point in Fig. 6 moved left first, then to the right following cycle 2. Conversely, although the elastic characteristic was also restored for floc 2 after cycle 2; this trend was not noted for floc 1 . In both cases, viscous characteristic has more signifi- cant effect on elasticity, indicating that the wastewater flocs are viscous-dominated objects.

\subsection{Detailed rheological response}

Certain sections on the floc images were marked to observe floc shape deformation in throughout freezing (left panel of Fig. 7 for floc 1, and left panel of Fig. 8 for floc 2). As freezing proceeded, all floc and stick markers were pushed upward (right panel in Figs. 7 and 8). The abscissas in Figs. 7 and 8 signify the vertical positions of the stick tip and ice front, both of which changed linearly throughout freezing. During cycles 1 and 2 for floc 1 , the vertical displacements of all markers on the floc followed closely those for the stick until the expanding ice overtook them and fixed them in space. The interior of original floc was stiff and resisted shape deformation under normal stress. The displacement of markers during cycle 1 was nonlinear, indicating that the floc interior structure was heterogeneous along the vertical axis (Fig. 7a). The displacement slopes versus $h$ curves obtained floc stiffness when subjected to normal stress. The floc interior was engulfed by ice over the range of $1300<h<1500 \mu \mathrm{m}$ and was less hard than that over the range $200<h<1300 \mu \mathrm{m}$, presenting a two-stage characteristic (Fig. 7a). 

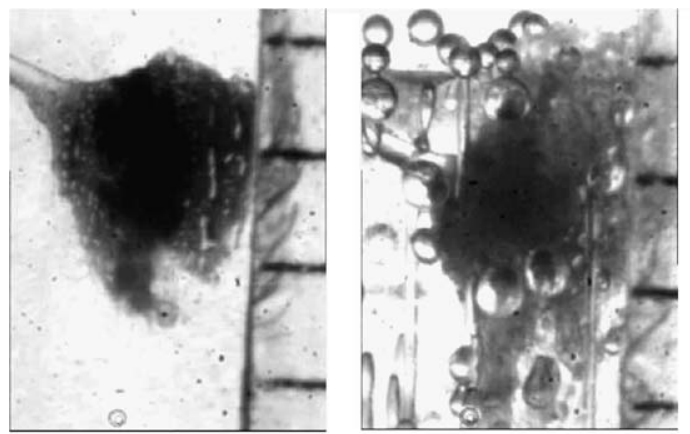

(a)
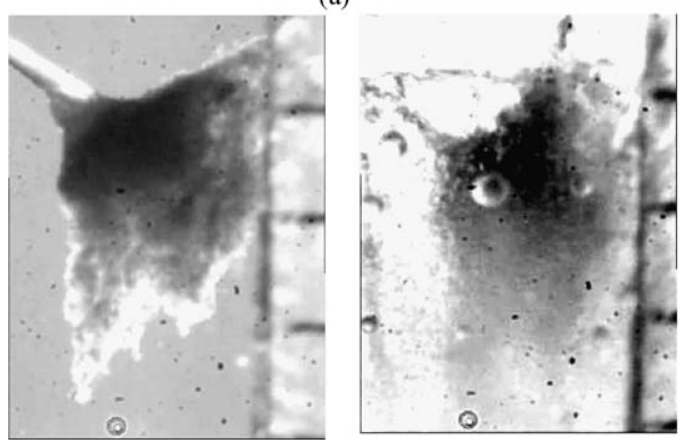

(c)
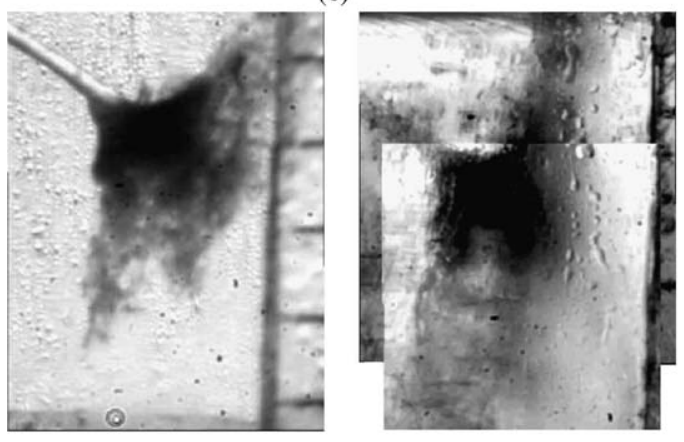

(e)

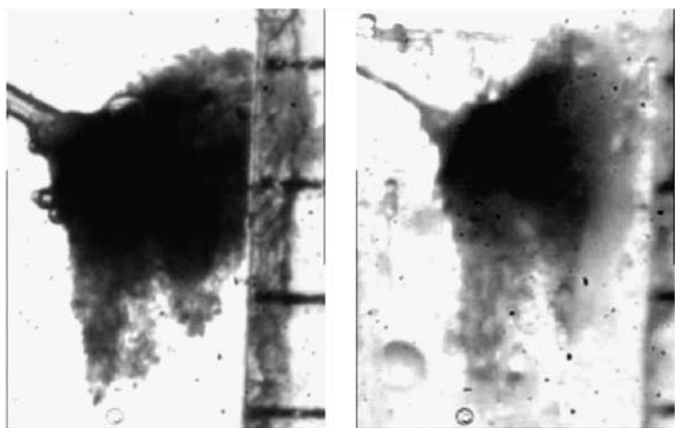

(b)
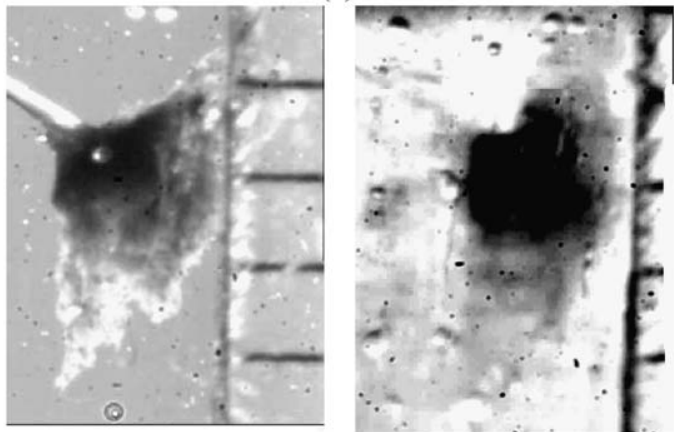

(d)
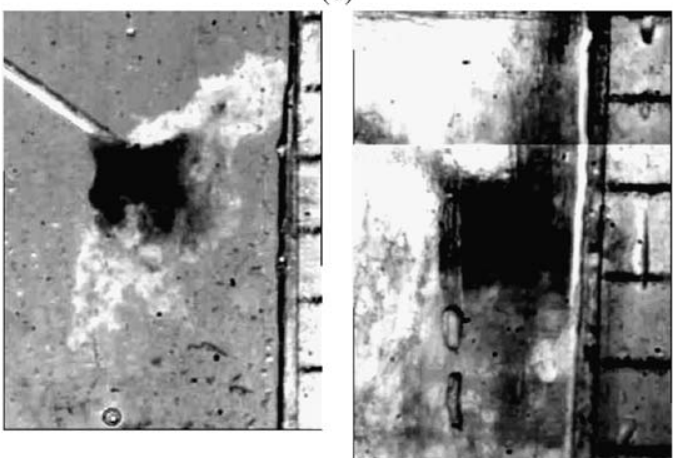

(f)

Fig. 4. Floc size variation for each cycling of freezing/thawing process of floc 2.

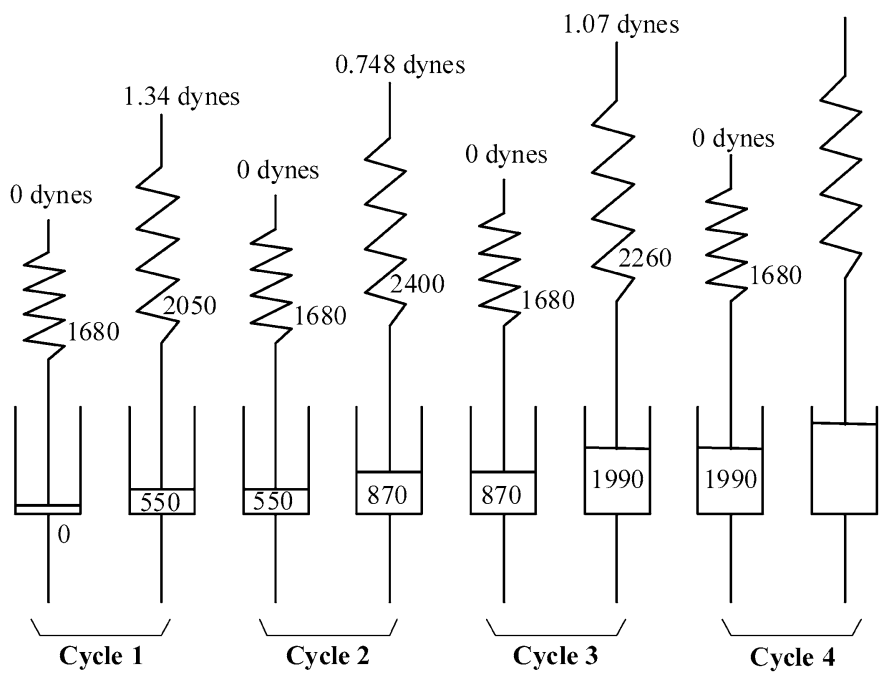

Fig. 5. The vertical displacements of floc 1 subjected to cyclic freezing and thawing. Maxwell model. In each cycle: left panel-floc vertical length before freezing; right panel-vertical length of completely frozen floc. Numerical values are in $\mu \mathrm{m}$.

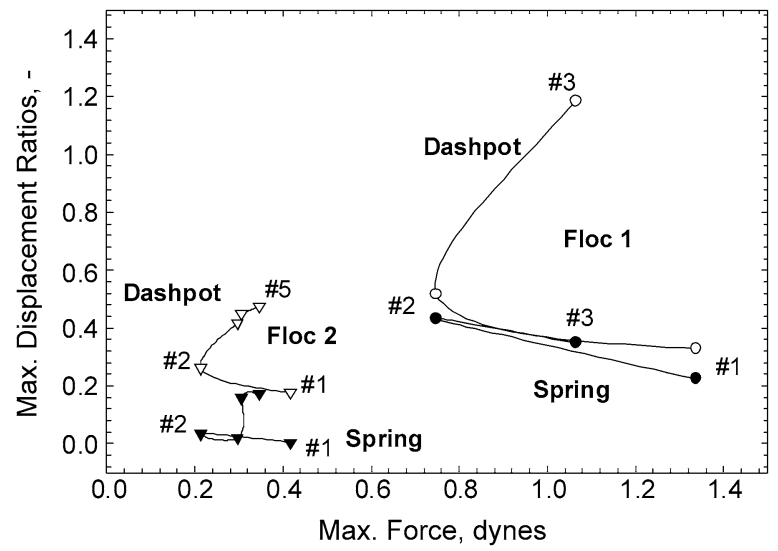

Fig. 6. Force-displacement relationships for floc 1 and floc 2. Close symbols are for spring element and open symbols are for dashpot element in Maxwell model.

Since floc shape was only partially restored after thawing stage in cycle 1 , the ice contacted the floc at an $h$ in cycle 2 $(=2230 \mu \mathrm{m})$ larger than that in cycle 1 (Fig. $7 \mathrm{~b})$. Cycle 2 

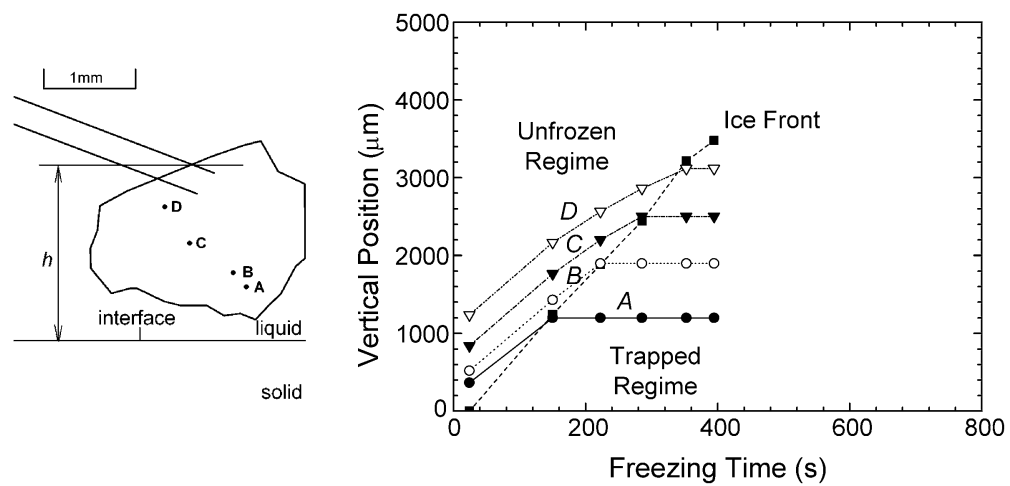

(a)
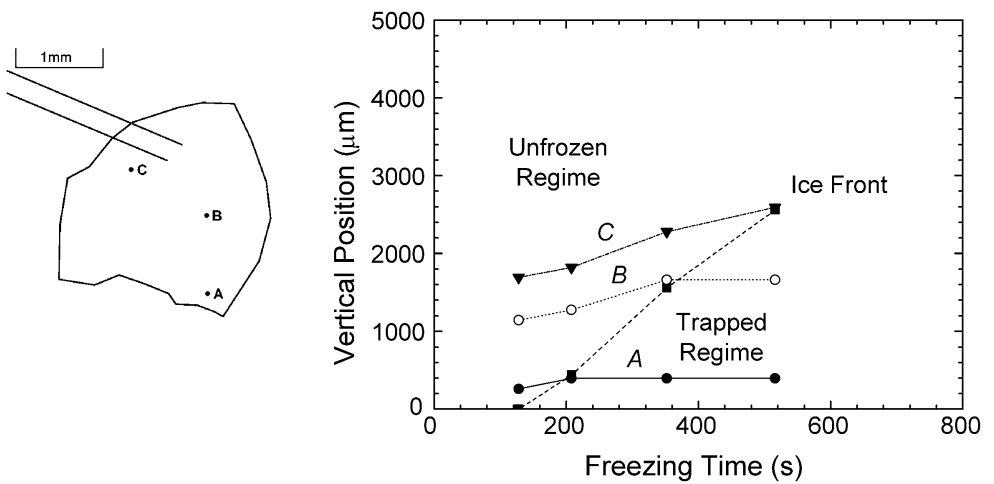

(b)
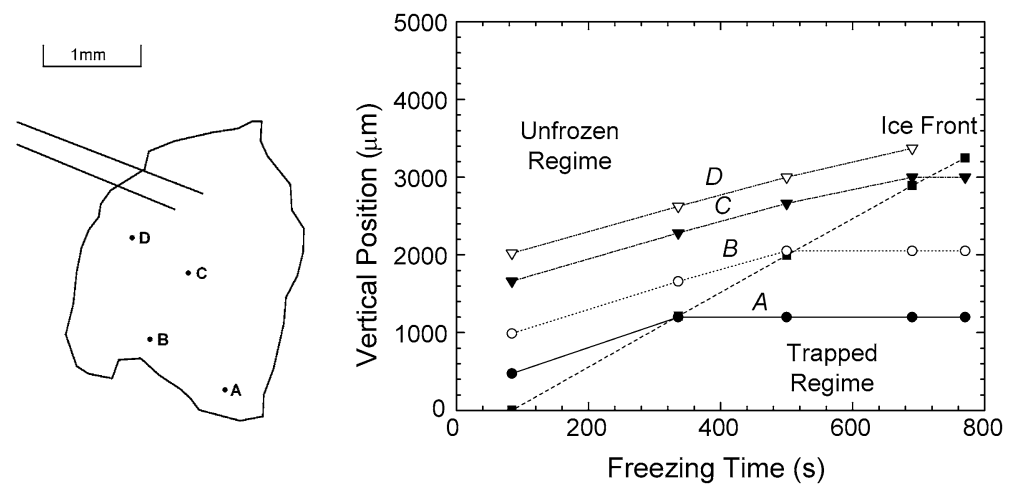

(c)
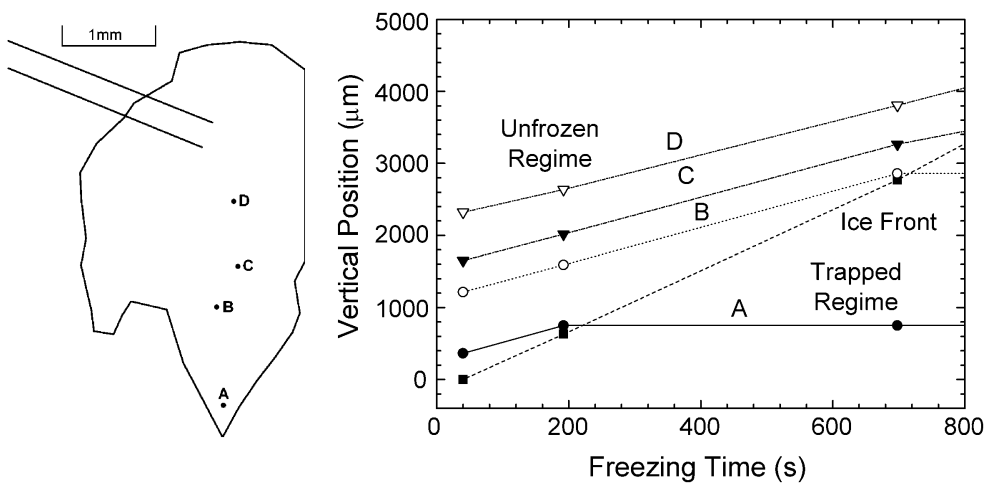

(d)

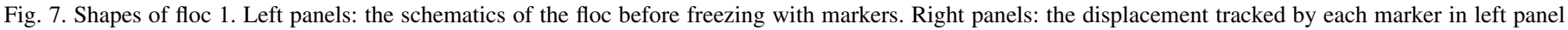
over freezing. (a) Cycle 1; (b) cycle 2, (c) cycle 3, (d) cycle 4.

generated an almost linear displacement curve; hence, the floc interior was "homogenized" by freezing and thawing throughout cycle 1 . The corresponding maximum vertical displacement of the stick $(1230 \mu \mathrm{m})$ in cycle 2 was smaller than that in cycle 1 $(2190 \mu \mathrm{m})$. The floc interior stiffness of was partially deteriorated throughout cycle 1 . 


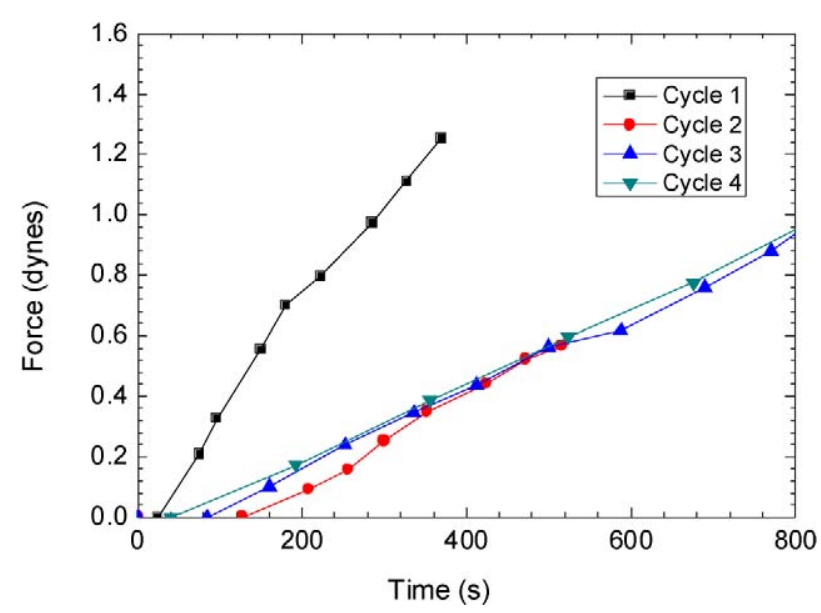

(a)

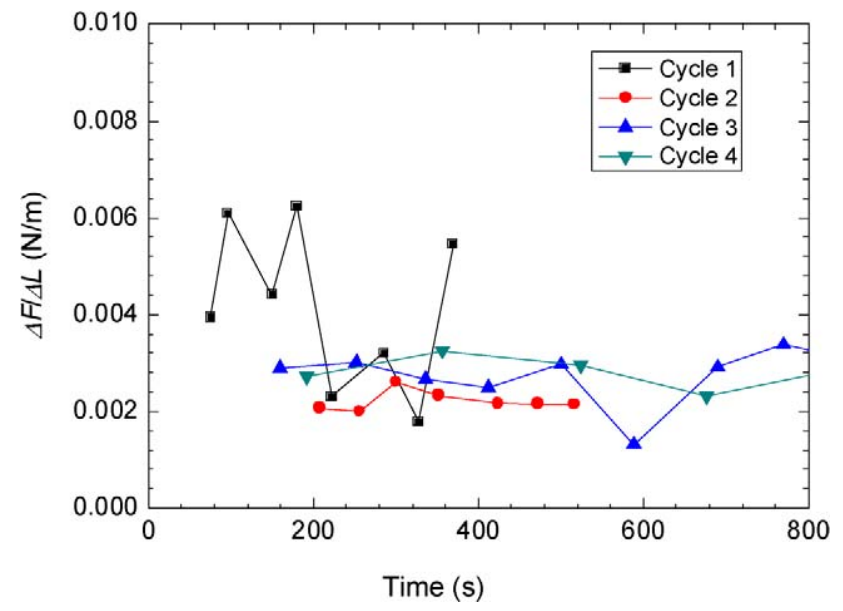

(b)

Fig. 8. Rheological behavior of floc 1 at different freezing time. (a) Force versus time curves. (b) Spring constant versus time curves.

The floc elongated after cycles 3 and 4 . Hence, the ice front contacted the floc bottom at $h=2550$ and $3670 \mu \mathrm{m}$ in cycle 3 (Fig. 7c) and cycle 4 (Fig. 7d), respectively. The displacement versus $h$ curves had steeper slopes in cycles 3 and 4 than in cycles 1 and 2. Therefore, floc interior stiffness was restored after cyclic freezing and thawing. A stiff and long floc generated an increased external force on the sludge floc after cyclic freezing and thawing.

Figs. $8 \mathrm{a}$ and $8 \mathrm{~b}$ present the respective forces applied to the floc by the ice front and increments of force with increments of shape elongation $(\Delta F / \Delta L)$ for floc 1 throughout cycles 1-4. The force versus time curve was linear; however, the $(\Delta F / \Delta L)$ ratio was high $(0.006 \mathrm{~N} / \mathrm{m})$ over the first $200 \mathrm{~s}$ of testing, and decreased to roughly $0.0025 \mathrm{~N} / \mathrm{m}$ in the latter stages of the test. In the following cycles, the force versus time curves all coincide, and all corresponding $(\Delta F / \Delta L)$ ratios were approximately $0.0025 \mathrm{~N} / \mathrm{m}$. That is, elongating a unit length of floc 1 requires an almost constant incremental increase in force after it was frozen and thawed once. Since floc 1 elongated after each freezing and thawing cycle, the force the ice front exerted on the floc increased following each cycle.

Conversely, the detailed shape deformation of floc 2 (Fig. 9) was similar to that of floc 1, except that floc 2 was softer and thereby easier to deform than floc 1, and was strongly correlated with displacement data (Fig. 6). Figs. 10a and 10b present the respective forces applied to both floc by the ice front and the incremental increase in force and shape elongation $(\Delta F / \Delta L)$ throughout cycles $1-6$. The original floc 2 had a dense "core" and a loose "tail" (Fig. 4a), whereas the core regime was shrank and the tail regime was elongated after freezing and thawing. Once the ice front contacted the loose tail, the force increased (Fig. 10a) in a nonlinear manner with time. Following cycle 1, the exerted force decreased; however, the force curve changed over cycles and did not converge to a single value. The corresponding $(\Delta F / \Delta L)$ ratio had a local maximum at which the ice front contacted the core regime of floc (Fig. 10b). That is, to elongate a unit length of the tail of floc would require less force than that required to elongate a unit length of the core of floc 2. Since the tail developed continuously after each cycle, the force built up accordingly.

Although flocs 1 and 2 were of similar shape and size and sampled from the same activated sludge stream, their rheological behaviors differed significantly. It is expected that during freezing and thawing, flocs in the same batch of wastewater sludge would respond very differently. This work determined how floc shape deforms when subjected to constant-speed freezing. The force exerted on the floc and the corresponding shape deformation corresponded to the observed structural change and reduction of bound water for frozen/thawed flocs [7]. Any comprehensive theoretical model should incorporate these experimental observations to elucidate to the interactions between a moving ice front and wastewater flocs. This study applied one-dimensional thermal gradient for exploring the rheological features of flocs. Further studies on the effects of three-dimensional thermal gradient on floc freezing are needed.

\section{Conclusions}

This study determined how wastewater sludge floc shape deforms when subjected to cyclic constant-speed freezing, and the estimated associated force applied by the ice front by measuring the deflection of a cantilevered stick. Two typical wastewater flocs (flocs 1 and 2) were tested. During freezing, both flocs were pulled apart by ice. During thawing, the floc shapes were only partially restored. The original floc 1 had a dense interior. The vertical length from the stick to the floc bottom was $1680 \mu \mathrm{m}$ and elongated to $2600 \mu \mathrm{m}$ after completely freezing during cycle 1 . The lengths for cycles 2-4 were 2230 and $3270 \mu \mathrm{m}, 2550$ and $4250 \mu \mathrm{m}$, and 3670 and $4720 \mu \mathrm{m}$, respectively. The corresponding maximum forces exerted on which floc by the ice front were $1.34,0.748,1.07$ and 1.51 dynes for cycles $1-4$. The lengths of floc 2 before and after freezing were 2040 and $2460 \mu \mathrm{m}, 2400$ and $2640 \mu \mathrm{m}, 2570$ and $2930 \mu \mathrm{m}, 2890$ and $3270 \mu \mathrm{m}, 2950$ and $3360 \mu \mathrm{m}$, and 3000 and $3710 \mu \mathrm{m}$ for cycles 1-6, respectively. The maximum force exerted on floc 2 throughout cycles $1-6$ were $0.428,0.214,0.297,0.306,0.347$, and 0.316 dynes, respectively. The Maxwell model applied to interpret the gross shape deformations in cyclic freezing and 

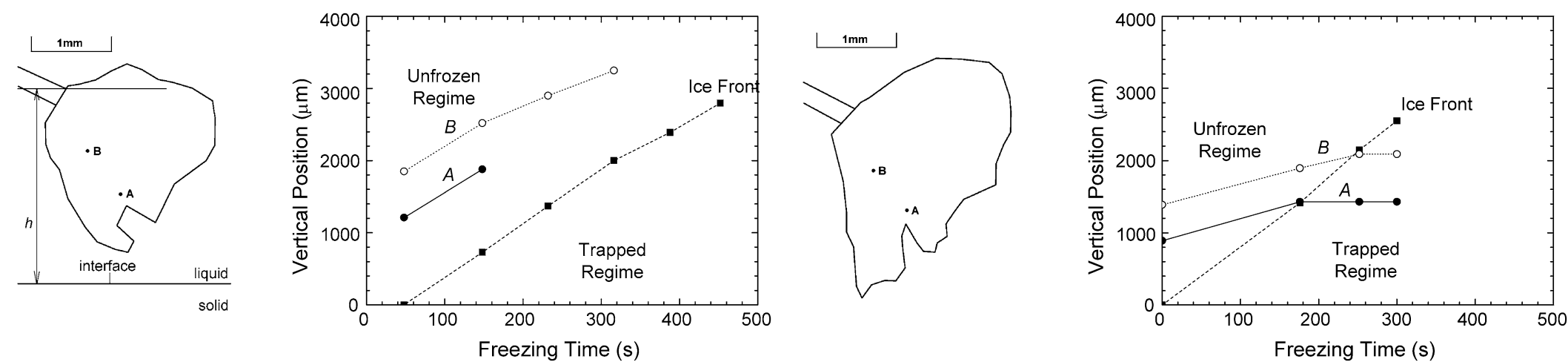

(a)
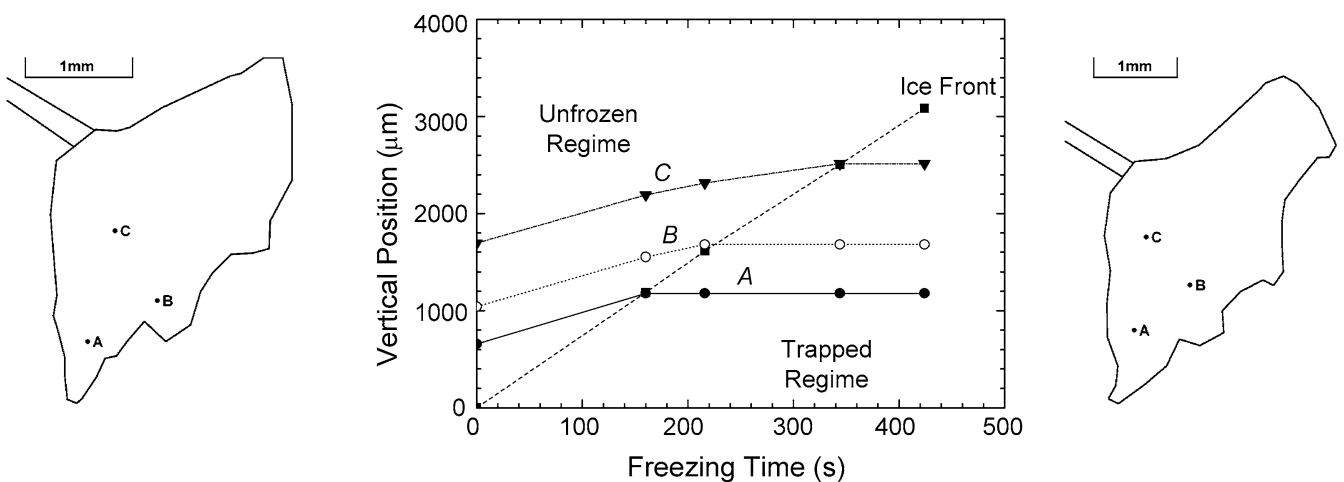

(c)
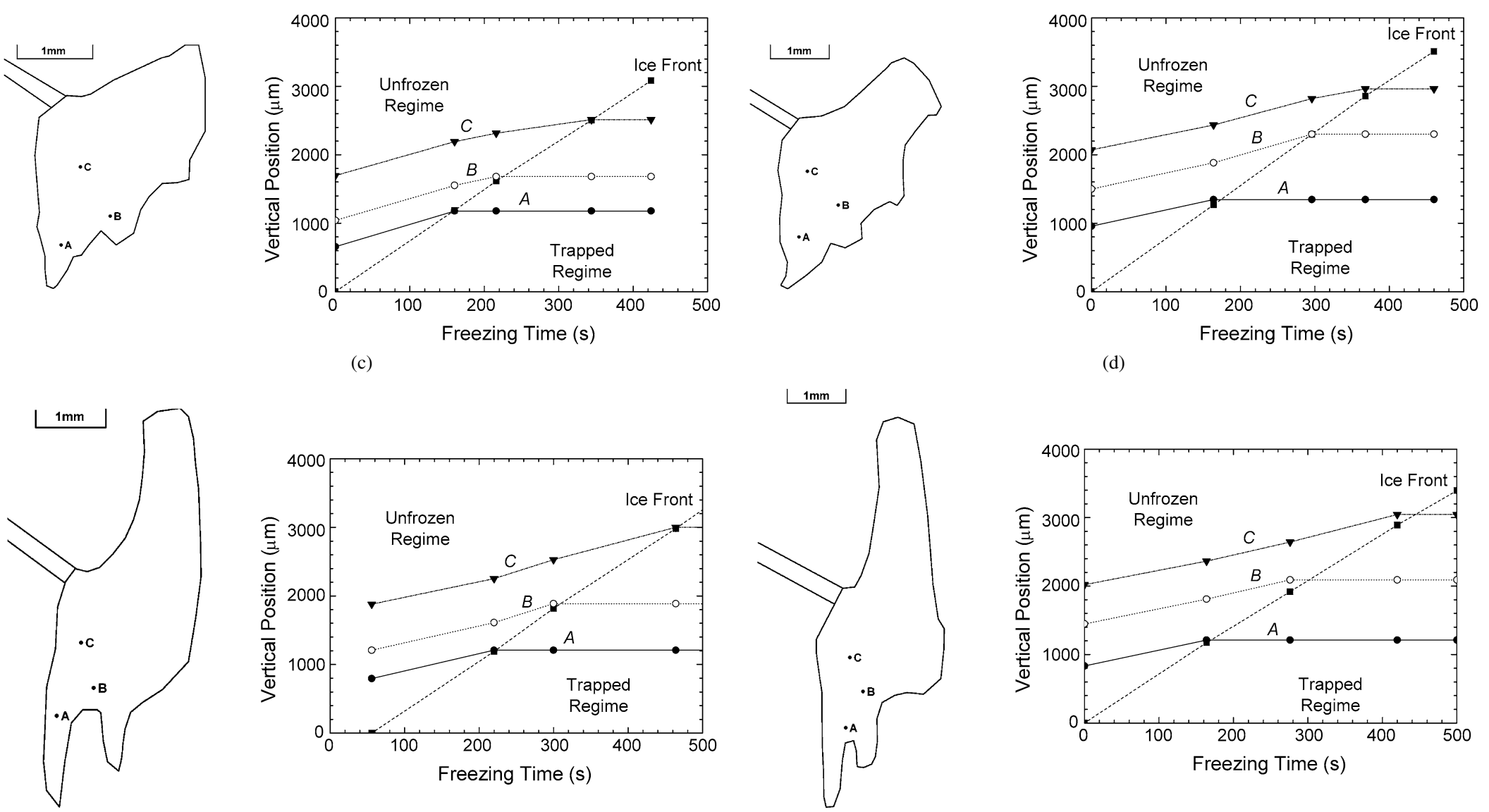

(e)

(f)

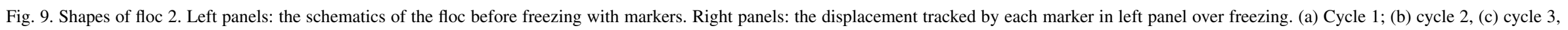
(d) cycle 4, (e) cycle 5, (f) cycle 6. 


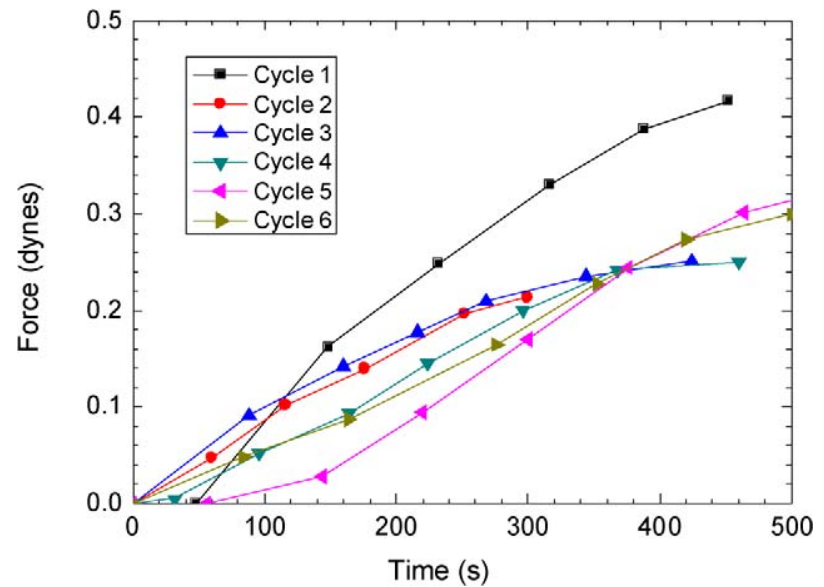

(a)

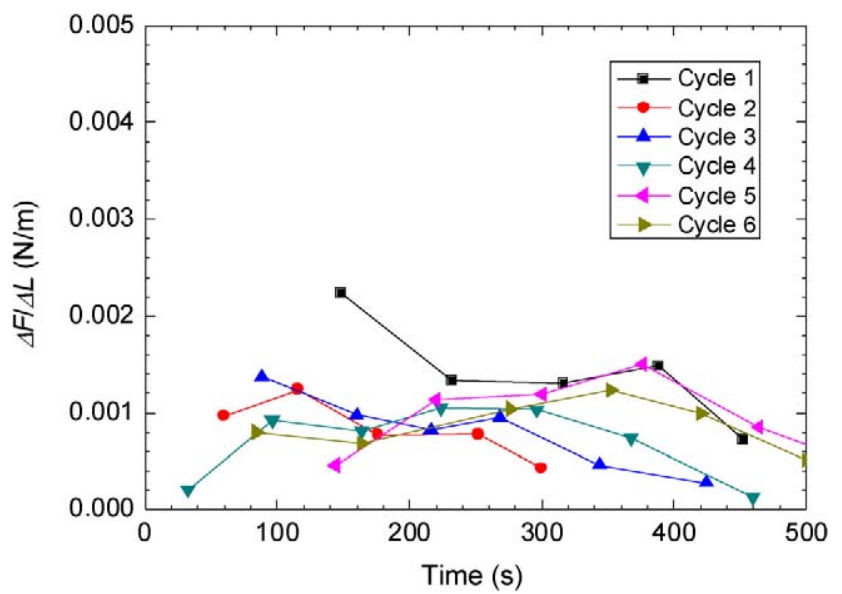

(b)

Fig. 10. Rheological behavior of floc 2 at different freezing time. (a) Force versus time curves. (b) Spring constant versus time curves.

thawing determined that both flocs were visco-elastic objects exhibiting time-varying rheological characteristics. The viscous characteristics of both flocs deteriorated after cycle 1 , and their strengths were restored after cycle 3 . The elastic characteristics have less significant role than the viscous contributions.

The detailed shape deformation of flocs was measured throughout cyclic freezing. The interior of floc 1 prior to freezing was stiffer than floc 2 and resisted shape deformation under normal stress. Furthermore, the floc interior is heterogeneous and had the so-called two-stage feature in the forcedisplacement relationship. To elongate a unit length of floc requires $0.006 \mathrm{~N}(\Delta F / \Delta L)$ to freeze the bottom section of the floc, and requires approximately $0.0025 \mathrm{~N}$ to freeze the top section of floc 1. Cycle 1 homogenized the floc structure, yielding a less varying force-displacement relationship during subsequent freezing and thawing cycles. Prior to freezing, floc $2 \mathrm{had}$ a dense "core" and a loose "tail," whereas the core shrank and the tail elongated after freezing and thawing. The corresponding $(\Delta F / \Delta L)$ ratio determined a local maximum at which the ice front contacted the floc core.

\section{References}

[1] W.R. Knocke, P. Trahem, Water Res. 23 (1989) 35.

[2] P.A. Vesilind, C.J. Martel, J. Environ. Eng. 116 (1990) 854.

[3] K. Kawasaki, A. Matsuda, Y. Mizukawa, J. Chem. Eng. Jpn. 24 (1991) 743.

[4] P.J. Parker, A.G. Collins, J.P. Dempsey, J. Environ. Eng. 124 (1998) 249.

[5] B. Ormeci, P.A. Vesilind, Water Res. 35 (2001) 4299.

[6] I.M.C. Lo, K.C.K. Lai, G.H. Chen, Environ. Sci. Technol. 35 (2001) 4691.

[7] D.J. Lee, Y.H. Hsu, Environ. Sci. Technol. 28 (1994) 1444.

[8] W.T. Hung, I.L. Chang, W.W. Lin, D.J. Lee, Environ. Sci. Technol. 30 (1996) 2391.

[9] D.J. Lee, Y.H. Hsu, Water Environ. Res. 67 (1995) 310.

[10] R. Asthana, S.N. Tewari, J. Mater. Sci. 28 (1993) 5414.

[11] C.P. Chu, W.H. Feng, Y.H. Tsai, D.J. Lee, Environ. Sci. Technol. 31 (1997) 1512.

[12] C.J. Martel, Water Res. 34 (2000) 657.

[13] A.K.C. Yeung, R. Pelton, J. Colloid Interface Sci. 184 (1996) 579.

[14] E.H. Poppele, R.M. Hozalski, J. Microbiol. Methods 55 (2003) 607.

[15] T. Tao, X.F. Peng, D.J. Lee, J. Colloid Interface Sci. 280 (2004) 409.

[16] T. Tao, X.F. Peng, D.J. Lee, J. Colloid Interface Sci. 290 (2005) 298. 